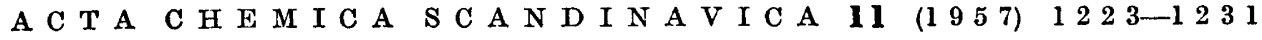

\title{
The Decrease of $\boldsymbol{F}^{\mathrm{k}}$-Integrals, Tetragonal Perturbations and Effects of Average Environment in the Reflection Spectra of Nickel(II) Complexes
}

\author{
OLE BOSTRUP and CHR. KLIXBULL J ØRGENSEN
}

Chemical Laboratories B and A, Technical University of Denmark, Copenhagen, Denmark

\begin{abstract}
The reflection spectra of 25 paramagnetic nickel(II) complexes are compared with the predictions of the ligand field theory for $d^{8}$ in $\mathrm{O}_{\mathrm{h}}$. The results are: the ligand field strength $\triangle$ can be implied in mixed complexes from the "rule of average environment" and is within $2 \%$ independent of atoms outside the first co-ordination sphere. The effects of tetragonal contributions to the ligand field are surprisingly small and can be empirically described by a certain deviation of the band differences. The integrals $F \mathrm{k}$, inversely proportional to the extension of the partly filled shell, are decreased 15$40 \%$ relative to the gaseous ion. As also found in molybdenum(III), the decrease has the same order of magnitude for $\gamma_{5}$ - and $\gamma_{3}$-electrons.
\end{abstract}

Tt is possible to apply ${ }^{1,2}$ the ligand field theory ${ }^{3,4}$ for $d^{8}$ in the symmetry $\mathrm{I}_{\mathrm{b}}$ to the absorption spectra of nickel(II) complexes in solution with some effects of intermediate coupling, intermixing levels with total spin $S=1$ and 0 . Hence, a nickel(II) complex can be characterized by two parameters, $\Delta$ (also called $\left(E_{1}-E_{2}\right)$ or $\left.10 \mathrm{Dq}\right)$ and the percentage decrease of the Slater-CondonShortley integrals $F^{\mathrm{k}}$. The deviation of the ligand field from spherical to octahedral-cubic symmetry determines $\Delta$, while the decrease of $F^{\mathrm{k}}$ is an effect of partly covalent bonding, decreasing the central field of spherical symmetry ${ }^{5}$, compared to the central field in the gaseous ion.

The present paper is a comparison of the absorption spectra of solutions with the reflection spectra of solid nickel(II) complexes. The study of absorption spectra of solutions and solids have differing advantages: In the former case, physico-chemical methods ${ }^{6}$ can prove the existence of complexes, of which no solid compounds are known. With modern spectrophotometers, the measurements of solutions can be made more easily, and a reliable molar extinction coefficient $\varepsilon$ can be found, while the reflection spectra present a monotonic, but not a linear, function of $\varepsilon$. The latter function cannot be predicted and depends on the pulverization etc.; although the effective light 
Table 1. Wavenumbers of band maxima of nickel(II) complexes. The excited levels are indicated. The unit is $1 \mathrm{kK}=1000 \mathrm{~K}=1000 \mathrm{~cm}^{-1}$.

\begin{tabular}{|c|}
\hline 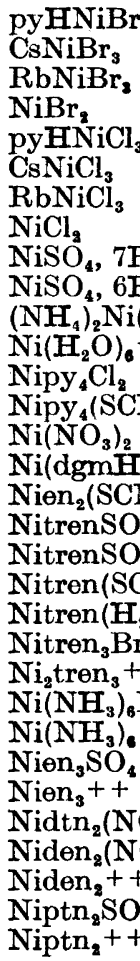 \\
\hline
\end{tabular}

$\begin{array}{cccccc}{ }^{3} \Gamma_{5}(\mathrm{~F}) & { }^{1} \Gamma_{3}(\mathrm{D}) & { }^{8} \Gamma_{4}(\mathrm{~F}) & { }^{1} \Gamma_{\mathrm{b}} & { }^{1} \Gamma_{\mathrm{c}} & { }^{3} \Gamma_{4}(\mathrm{P}) \\ - & (10.3) & 11.2 & 17.4 & - & 19.9 \\ - & (10.3) & 11.3 & 17.2 & - & 20.0 \\ - & (10.4) & 11.5 & 17.3 & - & 20.2 \\ - & (10.3) & 12.1 & (16.8) & - & 20.7 \\ - & (12.5) & 11.2 & (18.4) & - & 21.3 \\ - & (12.5) & (11.3) & 18.7 & - & 21.5 \\ - & (11.5) & (12.7) & 18.6 & (25.6) & 21.6 \\ - & (11.6) & 12.9 & 19.4 & (26.3) & 22.1 \\ 8.5 & (15.4) & (14.1) & (18.8) & (21.8) & 25.7 \\ 8.6 & (14.2) & (15.4) & (19.0) & (21.9) & 25.7 \\ 8.9 & (14.4) & (15.5) & (18.0) & (22.0) & 25.8 \\ 8.5 & (15.4) & (13.5) & (18.3) & (22.0) & 25.3 \\ 8.5 ; 10.9 & - & 15.9 & - & - & 25.7 \\ 10.1 & (12.8) & 16.7 & - & (22.7) & 26.7 \\ 10.15 & 13.5 & 16.5 & - & - & 27.0 \\ 10.9 & (12.9) & 17.1 & - & - & - \\ 9.7 & (12.3) & 17.7 & (15.6) & - & 28.0 \\ 10.0 & (12.9) & 17.2 & - & - & 26.9 \\ 10.6 & (12.9) & 17.9 & - & (23.3) & 27.5 \\ 10.9 & (12.8) & 17.9 & - & (23.3) & 27.8 \\ 10.5 & (12.8) & 17.8 & - & - & 27.8 \\ 11.2 & (12.9) & 18.4 & - & - & 28.1 \\ 10.7 & (12.5) & 18.3 & - & - & 28.7 \\ 10.8 & - & 17.7 & - & - & 28.2 \\ 10.75 & 13.15 & 17.5 & - & - & 28.2 \\ 11.3 & (12.8) & 18.5 & - & - & 29.0 \\ 11.2 & (12.4) & 18.35 & - & (24.0) & 29.0 \\ 11.0 & (12.6) & 18.1 & - & - & 28.2 \\ 11.2 & (12.4) & 18.9 & (16.3) & - & 28.6 \\ 11.5 & - & 18.7 & - & - & 29.1 \\ (11.6) & (12.6) & 19.3 & (17.5) & - & 29.5 \\ 11.2 & (12.5) & 19.0 & - & - & 29.7 \\ & & & & & \end{array}$

path is larger for coarse-grained than for fine-powdered material, it decreases with increasing $\varepsilon$, and for very high values of $\varepsilon$, a flat "roof" is observed of the band (corresponding to light scattering from the surface). Thus, only the position of the band can be measured exactly in the reflection spectrum; the relative heights of the bands and their half-w idths cannot easily be deduced from the data. On the other hand, the crystallogiaphic structure of solids may be known, and several complexes cannot be dissolved in any solvent without decomposition or isomerization.

Table 1 gives the observed maxima, while the Figures illustrate selected examples. The material of Table 1 is taken partly from other papers ${ }^{1,2,7,17}$. One of the most conspicuous results is the similarity between the spectra of a given complex in solution and in solid state. This is a special case of N. Bjerrum's rule ${ }^{8}$ that atoms outside the first co-ordination sphere have a very small influence on the absorption spectrum. This rule is valid mainly for the Laporteforbidden transitions within the partly filled shell of the complex (as explained by ligand field theory) while the electron transfer spectra can be more depend- 


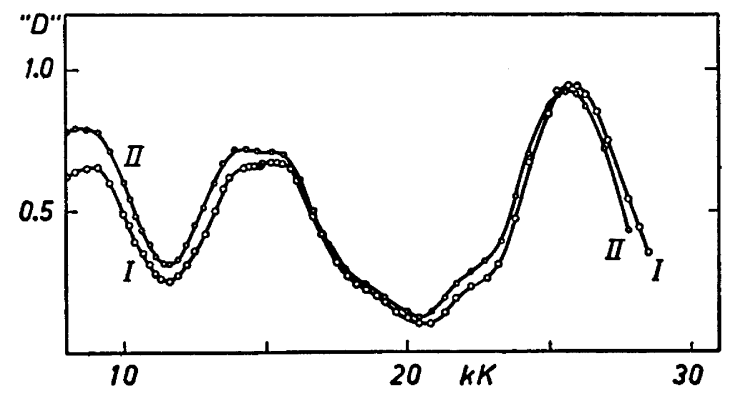

Fig. 1. Reflection spectra of I. $\left(\mathrm{NH}_{4}\right)_{2} \mathrm{Ni}\left(\mathrm{SO}_{4}\right)_{2}, 6 \mathrm{H}_{2} \mathrm{O}$ and II. $\mathrm{NiSO}_{4}, 7 \mathrm{H}_{2} \mathrm{O}$.

ent on the solvent 9,23 . The high bands of $\mathrm{Fe} o$-phen ${ }_{2}(\mathrm{CN})_{2}$ are, e.g., shifted $10 \%$, while most other solvent effects do not exceed $2 \%$.

It is seen from Fig. 1 that the Tutton salt $\left(\mathrm{NH}_{4}\right)_{2} \mathrm{Ni}\left(\mathrm{SO}_{4}\right)_{2}, 6 \mathrm{H}_{2} \mathrm{O}$ exhibits a slightly larger deviation from $\mathrm{Ni}\left(\mathrm{H}_{2} \mathrm{O}\right)_{6}{ }^{++}$in solution or in other salts. It is interesting that the double band in the red ${ }^{6}$, having ${ }^{3} \Gamma_{4}(\mathrm{~F})$ and ${ }^{1} \Gamma_{3}(\mathrm{D})$ as excited levels ${ }^{1}$, evolvès in the manner predicted ${ }^{1}$ for a larger $\triangle$ in the Tutton salt, viz. that the triplet percentage (and hence the intensity) wanders from the part with low to that with high wavenumber. Analogous to this greenish blue salt at room temperature, other samples, containing nickel(II) hexaaquo ions, turn sky-blue at the temperature of liquid air. Both the effects of crystal environment and temperature seem to be larger for aquo ions than for other complexes, perhaps caused by the changed polarization of the loosely bound water molecules.

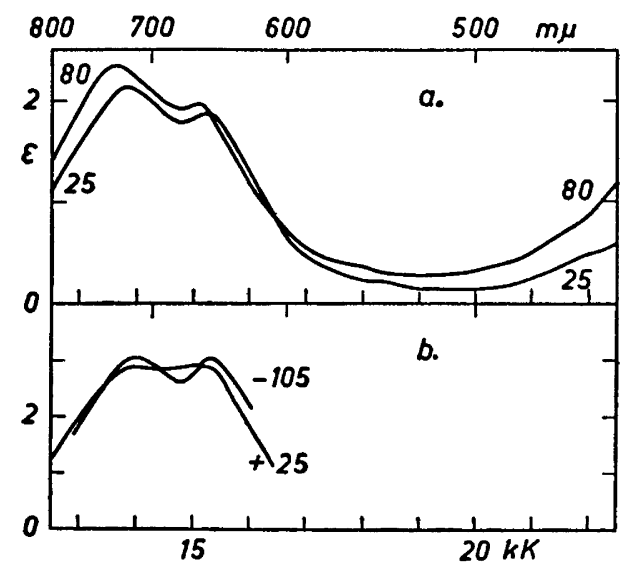

Fig. 2 a. Absorption spectra of $0.1 \mathrm{M} \mathrm{Ni}\left(\mathrm{ClO}_{4}\right)_{2}$ in $0.01 \mathrm{M} \mathrm{HClO}_{4}$ measured in $5 \mathrm{~cm}$ cells on a recording Cary spectrophotometer. at $25^{\circ}$ and $80^{\circ} \mathrm{C}$. b. Absorption spectra of $0.5 \mathrm{M}$ $\mathrm{Ni}\left(\mathrm{NO}_{3}\right)_{2}$ in $10 \%$ water, $40 \%$ glycerol $50 \%$ ethanol, measured by $\mathrm{Mr}$. Arne Jensen by photographic methods at $-105^{\circ}$ and $25^{\circ} \mathrm{C}$ as described in the experimental section.

Acta Chem. Scand. 11 (1957) No. 7 
Mr. A. Jensen of the Pharmaceutical College has kindly informed us about photographic measurements * of the spectrum of $0.05 \mathrm{M} \mathrm{Ni}\left(\mathrm{NO}_{3}\right)_{2}$ in $10 \%$ $\mathrm{H}_{2} \mathrm{O}, 40 \%$ glycerol, and $50 \%$ ethanol at $-105^{\circ} \mathrm{C}$, demonstrating similar effects (Fig. 2 b). Schäffer and Klixbüll Jørgensen have later measured the spectra of aqueous $\left.\mathrm{Ni} \mathrm{ClO}_{4}\right)_{2}$ at $25^{\circ} \mathrm{C}$ and $80^{\circ} \mathrm{C}$ on a Cary spectrophotometer (Fig. 2 a). In all cases, the effect of cooling resembles that of Tutton salt, compared to other nickel(II) salts.

Fig. 1 of Ref. ${ }^{7} \mathrm{~d}$-monstrates similar effects in the anhydrous chlorides and bromides. The position of ${ }^{1} \Gamma_{3}(\mathrm{D})$ might seem anomalously low. This effect is caused by the low values of $F^{\mathrm{k}}$-integrals in anion complexes $4,5,10 . \Delta$ is slightly larger in $\mathrm{NiCl}_{2}$ than in the double chlorides $\mathrm{MNiCl}_{3}$ and larger in $\mathrm{NiBr}_{2}$ than in $\mathrm{MNiBr}_{3}$, decreasing for increasing radii of the occurring anions and cations. All these compounds have an octahedral environment of six halide

atoms around each nickel atom.
Table 2 gives the values of $\triangle$ and ${ }^{2,4}$ the two quantities $B=\frac{1}{49} F^{2}-$ $\frac{5}{441} F^{4}$ and $C=\frac{5}{63} F^{4}$, derived from

$$
\begin{aligned}
& { }^{3} \mathrm{P}-{ }^{3} \mathrm{~F}=15 B=\sigma_{2}+\sigma_{3}-3 \Delta \text { with } \Delta=\sigma_{1} \\
& \frac{4}{7}\left({ }^{1} \mathrm{D}\right)+\frac{3}{7}\left({ }^{1} \mathrm{G}\right)-{ }^{3} \mathrm{~F}=8 B+2 C=\sigma\left({ }^{1} \Gamma_{3}\right)_{\text {corr }}
\end{aligned}
$$

$\sigma_{1}, \sigma_{2}, \sigma_{3}$ are the wavenumbers of the baricenters of the bands, representing transitions from ${ }^{3} \Gamma_{2}(\mathrm{~F})$ to ${ }^{3} \Gamma_{5}(\mathrm{~F}),{ }^{3} \Gamma_{4}(\mathrm{~F})$, and ${ }^{3} \Gamma_{4}(\mathrm{P})$, respectively. $\sigma_{1}$ is corrected for the effects of intermediate coupling ${ }^{1}$ and in some complexes inferred from the Orgel diagram, when $\sigma_{1}$ cannot be directly observed in the infra-red. $\sigma_{2}$ and $\sigma\left({ }^{1} \Gamma_{3}\right)$ are also corrected for the influence of intermediate coupling, when needed.

Table 2 gives the ratios $\beta_{1}$ and $\beta_{2}$ between the values of $15 B$ and $8 B+2 C$ in the complex and the gaseous ion, assuming the latter values to be $16900 \mathrm{~K}$ $\left(=\mathrm{cm}^{-1}\right)$ and $17900 \mathrm{~K}$, respectively. However, this is equivalent to assuming an effect of $(L, S)$-coupling $=-\frac{3}{2} \zeta_{3 \mathrm{~d}}=-950 \mathrm{~K}$ on the groundstate ${ }^{3} \Gamma_{2}{ }_{2}(\mathrm{~F})$. If the effect of $(L, S)$-coupling is completely quenched, all the ratios $\beta_{1}$ and $\beta_{2}$ mentioned above are increased by 0.06 from the values, given in Table 2 . If the interaction with ${ }^{1} \Gamma_{3}(\mathrm{G})$ is considered, $\beta_{2}$ is increased by $\sim 0.03$.

The decrease of $\beta$ from 1 seems to be a rather monotonic function of the extent of the partly covalent bonding. However, it cannot be assumed that $\sqrt{\beta}$ is exactly equal to the intermixing in the squares of the wavefunctions, $5,12,15$ forming linear combinations of atomic orbitals from the ligands and the nickel ion. It could not be assumed a priori that the molecular orbital theory might be applied to the complexes, assuming sharply defined configurations. However, the agreement of the Orgel diagram (the energy levels as function of $\Delta$ or rather ${ }^{3}$ of $\Delta / \beta$ ) with the gerade levels of $d^{n}$-complexes suggest that configuration interaction is relatively unimportant in the case of the $\gamma_{3^{-}}$and $\gamma_{5}$-subshells.

* These measurements were carried out at Chemistry Department A, where Mr. Arne Jensen worked as a guest with Professor J. Bjerrum. 
Table 2. The values of the parameters $\triangle, 15 B$, and $8 B+2 C$ in $\mathrm{kK}$ for nickel(II)-complexes in solid state and in aqueous solution. The ratios $\beta_{1}$ and $\beta_{2}$ of the two latter parameters, compared to those for the gaseous $\mathrm{Ni}^{++}$, are given. The observed energy difference $X_{\text {obs }}$ between ${ }^{3} \Gamma_{4}(\mathrm{~F})$ and ${ }^{3} \Gamma_{4}(\mathrm{P})$ is compared to $X_{\text {calc }}$ calculated from the ligand field symmetry $O_{\mathrm{h}}$ and the parameters $\triangle$ and $\beta_{1}$.

\begin{tabular}{|c|c|c|c|c|c|c|c|c|}
\hline & $\triangle$ & $15 B$ & $\beta_{1}$ & $8 B+2 C$ & $\beta_{2}$ & $X_{\text {obs }}$ & $X_{\text {calc }}$ & $X_{\mathrm{calc}}-\boldsymbol{X}_{\mathrm{obs}}$ \\
\hline pyHNiBr $_{3}$ & 6.8 & 11.7 & 0.71 & 10.6 & 0.59 & - & - & - \\
\hline $\mathrm{NiBr}$ & 7.3 & 10.9 & 0.65 & 10.4 & 0.58 & - & - & - \\
\hline pyHNiCl $_{3}$ & 7.0 & 11.9 & 0.71 & 12.1 & 0.68 & - & - & - \\
\hline $\mathrm{NiCl}_{2}$ & 7.6 & 11.3 & 0.67 & 12.0 & 0.67 & - & - & - \\
\hline $\mathrm{Ni}\left(\mathrm{H}_{2} \mathrm{O}\right)_{6}++$ & 8.5 & 14.1 & 0.84 & 14.7 & 0.82 & 11.0 & 11.3 & 0.3 \\
\hline $\mathrm{NiSO}_{4}, 7 \mathrm{H}_{2} \mathrm{O}$ & 8.5 & 14.9 & 0.88 & 14.8 & 0.83 & 11.0 & 11.9 & 0.9 \\
\hline $\mathrm{NiSO}_{4}, 6 \mathrm{H}_{2} \mathrm{O}$ & 8.6 & 14.7 & 0.87 & 14.8 & 0.83 & 10.9 & 11.7 & 0.8 \\
\hline$\left(\mathrm{NH}_{4}\right)_{2} \mathrm{Ni}\left(\mathrm{SO}_{4}\right)_{2}, 6 \mathrm{H}_{2} \mathrm{O}$ & 8.9 & 14.1 & 0.84 & 14.9 & 0.83 & 10.8 & 11.6 & 0.8 \\
\hline Niata- & 9.5 & 13.1 & 0.78 & 13.3 & 0.74 & 9.6 & 10.6 & 1.0 \\
\hline Niata gly $^{--}$ & 9.9 & 13.6 & 0.80 & 13.0 & 0.73 & 9.1 & 11.1 & 2.0 \\
\hline$\beta$-Nienta -- & 9.9 & 13.6 & 0.80 & 12.8 & 0.71 & 9.5 & 11.1 & 1.6 \\
\hline$\alpha$-Nienta ${ }^{--}$ & 10.1 & 12.9 & 0.76 & 12.7 & 0.71 & 9.2 & 10.6 & 1.4 \\
\hline $\mathrm{Nigly}_{3}^{-}$ & 10.1 & 13.9 & 0.82 & 13.1 & 0.73 & 11.0 & 11.3 & 0.3 \\
\hline Nienta en ${ }^{--}$ & 10.1 & 14.1 & 0.84 & 12.5 & 0.70 & 9.8 & 11.4 & 1.6 \\
\hline $\operatorname{Nienta}\left(\mathrm{NH}_{3}\right)^{--}$ & 10.2 & 13.5 & 0.80 & 12.7 & 0.71 & 9.7 & 11.0 & 1.3 \\
\hline $\mathrm{Ni}++$ in py & 10.2 & 12.9 & 0.76 & 13.5 & 0.75 & 10.5 & 10.6 & 0.1 \\
\hline $\mathrm{Nipy}_{4}(\mathrm{SCN})_{2}$ & 10.2 & 12.8 & 0.76 & 12.8 & 0.71 & 10.0 & 10.5 & 0.5 \\
\hline NitrenSO, & 10.3 & 13.2 & 0.78 & 12.7 & 0.71 & 9.7 & 10.8 & 1.1 \\
\hline Nien $\mathrm{gly}_{2}, \mathbf{a q}$ & 10.7 & 13.3 & 0.79 & 13.0 & 0.73 & 10.8 & 11.0 & 0.2 \\
\hline $\mathrm{Ni}\left(\mathrm{NH}_{3}\right)_{8}++$ & 10.8 & 13.4 & 0.79 & 13.1 & 0.73 & 10.7 & 11.0 & 0.3 \\
\hline $\mathrm{Ni}\left(\mathrm{NH}_{3}\right)_{6} \mathrm{Br}_{2} \cdot$ & 10.8 & 13.5 & 0.80 & - & - & 11.0 & 11.3 & 0.6 \\
\hline $\operatorname{Nitren}\left(\mathrm{H}_{2} \mathrm{O}\right)_{2}++$ & 10.9 & 12.9 & 0.76 & 12.6 & 0.70 & 10.0 & 10.8 & 0.8 \\
\hline NitrenSO, $7 \mathrm{H}_{2} \mathrm{O}$ & 11.0 & 12.4 & 0.73 & 12.7 & 0.71 & 9.6 & 10.5 & 0.9 \\
\hline Niata den ${ }^{-}$ & 11.1 & 13.0 & 0.77 & 12.5 & 0.70 & 11.1 & 10.9 & -0.2 \\
\hline $\mathrm{Nien}_{2} \mathrm{gly}^{+}$ & 11.1 & 13.2 & 0.78 & 12.5 & 0.70 & 10.7 & 11.0 & 0.3 \\
\hline Nitren $(\text { SCN })_{2}$ & 11.3 & 11.8 & 0.70 & 12.6 & 0.70 & 9.9 & 10.3 & 0.4 \\
\hline Nitetren++ & 11.3 & 13.0 & 0.77 & 12.4 & 0.69 & 10.1 & 11.0 & 0.9 \\
\hline $\operatorname{Nitn}_{3}++$ & 11.3 & 12.1 & 0.72 & 12.3 & 0.69 & 10.4 & 10.5 & 0.1 \\
\hline $\mathrm{Nidtn}_{2}\left(\mathrm{NO}_{3}\right)_{2}$ & 11.4 & 12.1 & 0.72 & 12.4 & 0.69 & 10.1 & 10.5 & 0.4 \\
\hline $\mathrm{Nibdn}_{3}++$ & 11.4 & 12.4 & 0.73 & 12.5 & 0.70 & 10.6 & 10.7 & 0.1 \\
\hline $\operatorname{Nitren}\left(\mathrm{NH}_{3}\right)_{\mathbf{2}}++$ & 11.4 & 12.4 & 0.73 & 12.2 & 0.68 & 10.0 & 10.7 & 0.7 \\
\hline Nitren en ++ & 11.4 & 13.5 & 0.80 & 12.2 & 0.68 & 10.3 & 11.3 & 1.0 \\
\hline NitetrenNH $_{3}++$ & 11.5 & 12.8 & 0.76 & 12.2 & 0.68 & 9.9 & 10.9 & 1.0 \\
\hline $\operatorname{Niden}_{2}++$ & 11.5 & 13.3 & 0.78 & - & - & 10.4 & 11.1 & 0.7 \\
\hline Nitren gly + & 11.6 & 12.2 & 0.72 & 12.4 & 0.69 & 9.4 & 10.6 & 1.2 \\
\hline $\operatorname{Niden}_{2}\left(\mathrm{NO}_{3}\right)_{2}$ & 11.6 & 12.7 & 0.75 & 12.2 & 0.68 & 9.7 & 11.0 & 1.3 \\
\hline $\mathrm{Ni}_{2}$ tren $_{3} \mathrm{Br}_{4}$ & 11.6 & 11.7 & 0.69 & 12.6 & 0.70 & 9.7 & 10.5 & 0.8 \\
\hline $\mathrm{Nien}_{3}++$ & 11.6 & 12.5 & 0.74 & 12.2 & 0.68 & 10.7 & 10.8 & 0.1 \\
\hline $\mathrm{Nien}_{3} \mathrm{SO}_{4}$ & 11.7 & 12.4 & 0.73 & 12.6 & 0.70 & 10.5 & 10.8 & 0.3 \\
\hline $\operatorname{Niptn}_{2}^{++}$ & 11.8 & 13.3 & 0.79 & 12.3 & 0.69 & 10.7 & 11.3 & 0.6 \\
\hline Nip & 12 & 12.5 & 0.74 & 12.4 & 0.69 & 10.2 & 11.0 & 0.8 \\
\hline
\end{tabular}

There is no doubt that $\gamma_{3}$-electrons are more anti-bonding than $\gamma_{5}$-electrons in all octahedral $\mathrm{d}^{\mathrm{n}}$-complexes, i.e, $\triangle$ is positive, agreeing with $\sigma$-bonding in the direction from the ligands to the central ion, or $\pi$-bonding in the opposite direction. If $\pi$-bonding from the ligands occurs, it decreases $\triangle$. It might thus be presumed that sub-shell configurations with many $\gamma_{3}$-electrons would exhibit larger effects of partly covalent bonding than the less anti-bonding configurations. It is seen from Table 2 that $\beta$ is not essentially different for $15 B$, 
derived from $\gamma_{5}^{5}{\gamma_{3}}^{3}$ and $\gamma_{5}^{4} \gamma_{3}{ }^{4}$ and for $8 B+2 C$, derived from $\gamma_{5}^{6}{\gamma_{3}}^{2}$. Similar evidence is obtained ${ }^{14}$ from molybdenum(III) in $\mathrm{MoCl}_{5}\left(\mathrm{H}_{2} \mathrm{O}\right)^{--}$, where both the positions of ${ }^{2} \Gamma_{3}$ and ${ }^{2} \Gamma_{5}$ of $\gamma_{5}{ }^{3}$ and ${ }^{4} \Gamma_{5}$ and ${ }^{4} \Gamma_{4}$ of $\gamma_{5}{ }^{2} \gamma_{3}$ and $\gamma_{5} \gamma_{3}{ }^{2}$, relative to the $\gamma_{5}^{3}$-groundlevel ${ }^{4} \Gamma_{2}$, can be explained by the set $B=450 \mathrm{~K}$ and $C=$ $=1800 \mathrm{~K}$. Hence, the decrease of $\beta$ is equally effective for $\gamma_{5}$ and $\gamma_{3}$ electrons.

It is surprising that Jahn-Teller distorted systems such as vanadium(IV) 14 and copper(II) ${ }^{1,2,15}$ have a ligand field of distinctly tetrago al symmetry, $\mathrm{D}_{4 \mathrm{~h}}$, even when the ligands are nearly or completely identical, while on the other hand, the regular $\mathrm{d}^{3}-, \mathrm{d}^{5}-, \mathrm{d}^{6}$ - and $\mathrm{d}^{8}$-systems (with $S==\frac{3}{2}, \frac{5}{2}, 0$ and 1 , respectively) agree very nicely with the theory for the cubic-octahedral symmetry $\mathrm{O}_{h}$ with only one ligand field parameter $\Delta$.

In chromium(III) and cobalt(III) complexes ${ }^{10}$, the deviations from $\mathrm{O}_{\mathrm{h}}$ are not conspicuous, even in the case of highly different ligands. This is even more pronounced in the case of nickel(II) complexes ${ }^{1,2}$ in solution. The latter effect can be explained by the insufficient difference between $\mathrm{N}$ and $\mathrm{O}$ in Tsuchida's spectrochemical series, which can be written ${ }^{16}$

$$
\mathrm{Br}<\mathrm{Cl}<\mathrm{F}<\mathrm{O}<\mathrm{N}<\mathrm{C}
$$

according to the bonding atom of the ligand. Table 1 gives one probable case of tetragonal splitting *, trans- $\mathrm{Ni} \mathrm{py}_{4} \mathrm{Cl}_{2}$, where the level ${ }^{3} \Gamma_{5}(\mathrm{~F})$ is markedly split, analogous ${ }^{10}$ to ${ }^{4} \Gamma_{5}(\mathrm{~F})$ of trans-Cr en $_{2} \mathrm{Cl}_{2}{ }^{+}$, corresponding to the larger difference between $\mathrm{Cl}$ and $\mathrm{N}$.

Since no tetragonal splitting generally can be perceived, the rule of "average environment" can be directly applied to the absorption bands, viz. that they correspond to an average value of $\Delta$, found by interpolation between $\Delta$ for the complexes with six equal ligand atoms. Tables 1 and 2 extend the investigated class of "average environments" considerably, as discussed by Asmussen and Bostrup in the case of polyamine nickel(II) complexes ${ }^{17}$. Especially, the tetradentate amine tren is shown to form no tetrahedral complexes in solid state ${ }^{17}$, but to have two residual places for other ligands ${ }^{2}$ (cf. also Ref..$^{18}$ ).

Even though a genuine tetragonal splitting has been found only in $\mathrm{Ni}$ $\mathrm{py}_{4} \mathrm{Cl}_{2}$, it is possible to dinstinguish between purely cubic and tetragonally distorted complexes by a closer study of the observed wavenumbers: The two levels ${ }^{3} \Gamma_{4}(\mathrm{~F})$ and ${ }^{3} \Gamma_{4}(\mathrm{P})$ have energies, which are the roots $E$ in the weak field determinant

$$
\left|\begin{array}{cc}
0.6 \triangle-E & 0.4 \triangle \\
0.4 & 15 B-E
\end{array}\right|=0
$$

* The trans-configuration is demonstrated by Porai-Koshits ${ }^{11}$ from crystallographic X-ray studies. The compound has the same spectrum in anhydrous pyridine and in ethanol with maxima at the same wavenumbers as the solid. By addition of $10 \%$ water to the ethanolic solution, or more water to the pyridine, the greenish blue colour is changed to sky-blue with the same maxima as produced by $\mathrm{Ni}\left(\mathrm{NO}_{3}\right)_{2}$ in pyridine. Hence, the Katzin effect ${ }^{18}$ seems to occur in the exchange of chloride and water on the two residual places of $\mathrm{Ni}_{\mathrm{py}}++$, when dissolved in an organic solvent. 
or the equivalent strong field determinant

$$
\begin{array}{cc}
3 B+0.8 \triangle-E & 6 B \\
6 B & 12 B-0.2 \triangle-E
\end{array} \mid=0
$$

if the energy of the groundlevel ${ }^{3} \Gamma_{2}(\mathrm{~F})$ is written $-1.2 \triangle$. Thus, with two parameters $\triangle$ and $B$, the three spin-allowed bands $\sigma_{1}, \sigma_{2}$, and $\sigma_{3}$ can be described. It is possible to compare the distance $X_{\text {obs }}$ between the two bands $\sigma_{2}$ and $\sigma_{3}$ with the distance between the two roots $E$

$$
X_{\text {calc }}=\sqrt{225 B^{2}-18 B \Delta+\triangle^{2}}
$$

Table 2 demonstrates that within the uncertainty of the parameters $\triangle$ and $B$ (amounting to 0.2 or $0.3 \mathrm{kK}$ in $X_{\text {calc }}$ ) the complexes with six identical ligands have $X_{\text {obs }}=X_{\text {calc }}$, while for the tetragonal complexes, $X_{\text {calc }}$ is $600-2000 \mathrm{~K}$ larger than $X_{\text {obs. }}$. When $X_{\text {calc }}-X_{\text {obs }}$ is very large, the treatment in Table 2 loses some of its validity; in this case, $\triangle$ is undoubtedly larger than indicated by $\sigma_{1}$, and $15 B$ thus calculated too large.

The deviation from the conservation of baricenters is probably caused by the interaction of the three ${ }^{3} \Gamma_{\mathrm{t}_{5}}$ levels. Schäffer and one of the authors ${ }^{1.9}$ have discussed this problem. On the analogy of chromium(III) complexes, the tetragonal splitting is expected to occur in a complex with weaker ligand field along the tetragonal axis than along the two axes in the plane:
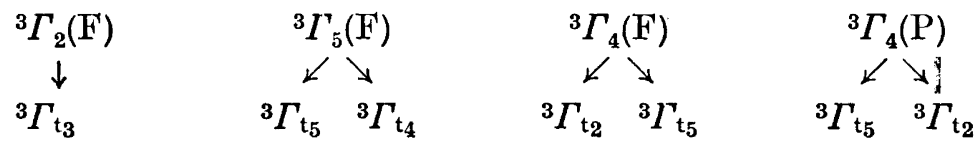

However, the splitting is smaller than expected from any electrostatic model. The effect in Table 2 is probably connected with the fact that the maximum absorption occurs in the doubly degenerate part ${ }^{3} \Gamma_{\mathrm{t}_{5}}$ of the bands ${ }^{3} \Gamma_{4}$.

It is seen from Table 2 that $\mathrm{SCN}^{-}$introduces a slightly larger value of $\Delta$ than the corresponding aquo complexes. By comparison of the data for $\mathrm{Ni}$ $\mathrm{py}_{4}(\mathrm{SCN})_{2}$ and nickel(II) nitrate in $90 \%$ pyridine ${ }^{2}$, the latter complex probably contains only four molecules py, as previously foreseen. It is seen from Table 1 that the blue hydrochloride of nickel(II) dimethylglyoximate ${ }^{20}$ has a large ligand field strength $\Delta$.

The last problem to be discussed in this paper is the identification of the two next singlet levels ${ }^{1} \Gamma_{\mathrm{b}}$ and ${ }^{1} \Gamma_{\mathrm{c}}$ of Table 1 . The three most probable levels are ${ }^{1} \Gamma_{1}(\mathrm{G})$ of $\gamma_{5}{ }^{6} \gamma_{3}{ }^{2}$ and ${ }^{1} \Gamma_{5}(\mathrm{D})$ and ${ }^{1} \Gamma_{4}(\mathrm{G})$ of $\gamma_{5}{ }^{5} \gamma_{3}{ }^{3}$. The slope of ${ }^{1} \Gamma_{\mathrm{c}}$ as function of $\triangle$ indicates that it is ${ }^{1} \Gamma_{5}(D)$ with the wavenumber $\sigma \cong \triangle+8 B+2 C$, except in $\mathrm{RbNiCl}_{3}$ and $\mathrm{NiCl}_{2}$. It has previously been discussed ${ }^{2}$ whether ${ }^{1} \Gamma_{\mathrm{b}}$ $\sim 15 \mathrm{kK}$ is caused by a tetragonal splitting or is ${ }^{1} \Gamma_{1}(\mathrm{G})$ with a highly decreased value of $\sigma \cong 16 B+4 C$. Hence, ${ }^{1} \Gamma_{4}(\mathrm{G})$ with $\sigma \cong \triangle+12 B+2 C$, is probably in most cases situated at a slightly higher wavenumber than ${ }^{3} \Gamma_{4}(\mathrm{P})$.

The main result of this paper is that the ligand field theory can be applied to paramagnetic nickel(II) complexes, both in solid state and in solution, with assumption of octahedral symmetry and one ligand field parameter $\Delta$, if one

Acta Chem. Scand. 11 (1957) No. 7 
further variation is admitted: the parameters $F^{\mathbf{k}}$ (i.e. $B$ and $C$ ) are multiplied by a factor $0.5<\beta<1$ in complexes, compared to gaseous $\mathrm{Ni}^{++}$. Even though the levels may show individual behaviour, caused by interaction with other levels having the same $S$ and $\Gamma_{\mathrm{n}}$, it seems demonstrated that the partly filled shell is expanded, relative to the $3 \mathrm{~d}$-shell in $\mathrm{Ni}^{++}$. This expansion has the same order of magnitude in the $\gamma_{3}$ - and $\gamma_{5}$-sub-shells. The final explanation of this by molecular orbital theory will probably be rather complicated. However, the present authors believe that the ligand field theory is remarkably close, $\sim 2 \%$, in predicting the $\mathrm{d}^{\mathrm{n}}$-energy levels, if the wavefunctions of the partly filled shell are written as antisymmetrized products of orbitals, each being the product of a hydrogen-like angular part (influenced by the group-theoretical conditions of the complex) and a radial part. The latter varies from one complex to another as indicated by the variation of the parameters $F^{\mathbf{k}}$ of electrostatic interaction between the electrons in a mainly spherical symmetrical field ${ }^{5}$.

\section{EXPERIMENTAL}

The preparation and the analyses of the solid nickel(II) compounds are described elsewhere $7,11,17,20$. The ligands are abbreviated:

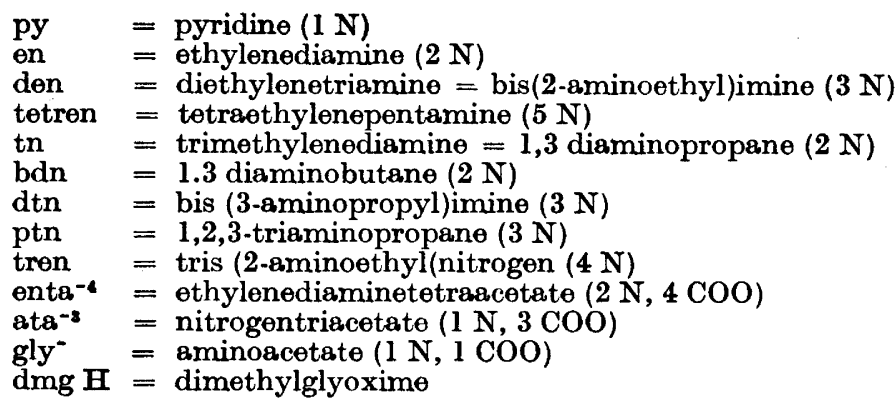

The numbers in parentheses denote the number of nitrogen atoms and carboxyl groups available for co-ordination.

The reflection spectra were measured on the Beckman DU spectrophotometer. The absorption spectra of solutions were measured in the infra-red on this instrument and in the visible on the Cary MS-11 recording spectrophotometer.

$\mathrm{Mr}$. Arne Jensen determined the absorption spectra of $0.05 \mathrm{M} \mathrm{Ni}\left(\mathrm{NO}_{3}\right)_{2}$ in a mixture of 10 volume $\% \mathrm{H}_{2} \mathrm{O}, 40 \%$ glycerol and $50 \%$ ethanol with a Zeiss spectrograph. The solutions were contained in a test tube, suspended in a double-wall plestic box, $20 \times 20 \times 20 \mathrm{~cm}$. In the bottom of this box, liquid air was placed in order to evade condensation of ice inside the box, and the test tube was cooled by immersion in the liquid air. The tempere. ture was measured with a thermoelement. The Schwarzschild exponent $p$ was determined for the photographic plate, according to Kortüm ${ }^{21}$. The extinction coefficients were determined by comparison with the spectrum of the mixture, which was both photographed and measured on the Cary spectrophotometer. Since $\varepsilon$ is definitely larger than for the aquo ion (cf. Ref. ${ }^{22}$ ), solvates with glycerol or nitrate must occur. It cannot be excluded that the composition of the solution changes with temperature, caused by the heat of formation of these complexes. However, a definite narrowing and shift towards higher wavenumbers by cooling can be inferred from Mr. Arne Jensen's measurements, and Mr. Claus E. Schäffer and Klixbüll Jørgensen have later determined on the Cary the effect on $0.1 \mathrm{M} \mathrm{Ni}\left(\mathrm{ClO}_{4}\right)_{2}$ in $5 \mathrm{~cm}$ layer of aqueous solution of warming from $25^{\circ} \mathrm{C}$ to $80^{\circ} \mathrm{C}$, and obtained the predicted change: broadening and bathochromic shift of the bands, and the change of singlet-triplet intermixing corresponding to a decreased value of $\Delta$. 
Acknowledgments: We thank Mr. C. J. Ballhausen and Professor Jannik Bjerrum for having drawn our attention to the effect of temperature on the absorption spectrum of nickel(II) salts. Further, we are indebted to Dr. F. G. Mann, Cambridge, who provided samples of tren-and ptn-complexes. Finally, we want to thank Professor R. W. Asmussen for many valuable discussions.

\section{REFERENCES}

1. Jørgensen,.C. Klixbüll, Acta Chem. Scand. 9 (1955) 1362.

2. Jørgensen, C. Klixbüll, Acta Chem. Scand. 10 (1956) 887.

3. Tanabe, Y. and Sugano, S. J. Phys. Soc. Japan 9 (1954) 753, 766.

4. Jørgensen, C. Klixbül, Quelques Problèmes de Chimie Minérale. Dixieme Conseil de Chimie. Institut International de Chimie Solvay. R. Stoops, Bruxelles 1956, p. 355.

5. Jørgensen, C. Klixbüll, Energy Levels of Complexes and Gaseous Ions. Gjellerups Forlag, Copenhagen 1957.

6. Bjerrum, J. Metal Ammine Formation in Aqueous Solution. Thesis. Copenhagen 1941.

7. Asmussen, R. W. and Bostrup, O. Acta Chem. Scand. 11 (1957) 745.

8. Bjerrum, N. Z. anorg. Chem. 63 (1909) 140.

9. Bjerrum, J., Adamson, A. W., and Bostrup, O. Acta Chem. Scand. 10 (1956) 329.

10. Schäffer, C. E. To be published.

11. Porai-Koshits, M. A. Trudy Inst. Krist. Akad. Nauk SSSR 10 (1954) 117 and Doklady Akad. Nauk SSSR 92 (1953) 333.

12. Jørgensen, C. Klixbüll, Kgl. Danske Videnskab. Selskab, Mat. fys. Medd. 30 (1956) No. 22.

13. Jørgensen, C. Klixbüll, Acta Chem. Scand. 11 (1957) 53.

14. Jørgensen, C. Klixbüll, Acta Chem. Scand. 11 (1957) 73.

15. Bjerrum, J., Ballhausen, C. J. and Jørgensen, C. Klixbüll, Acta Chem. Scand. 8 (1954) 1275.

16. Bostrup, O. and Jørgensen, C. Klixbüll, Acta Chem. Scand. 10 (1956) 1501.

17. Asmussen, R. W. and Bostrup, O. Acta Chem. Scand. 11 (1957) 1097.

18. Jørgensen, C. Klixbüll, Acta Chem. Scand. 11 (1957) 399.

19. Schäffer, C. E. and Jørgensen, C. Klixbüll, Acta Chem. Scand. To be published.

20. Asmussen, R. W. Studies in the Magnetochemistry of Incrg. Complex Compounds (in Danish) Copenhagen. 1944.

21. Kortüm, G. Kolorimetrie, Photometrie und Spectrophotometrie, 3. ed. 1955, p. 388.

22. Jørgensen, C. Klixbüll, Acta Chem. Scand. 8 (1954) 175.

23. Nakamoto, K., Kobayashi, M., and Tsuchida, R. J. Chem. Phys. 22 (1954) 957.

Received April 15, 1957. 